\title{
Surface Modification of Metallic Targets with Ultrashort Laser Pulses
}

\author{
B. Gakovic ${ }^{a}$, J. $_{\text {Stasic }}^{a, *}, \mathrm{~S} \operatorname{Petrovic}^{a}, \mathrm{~B} \mathrm{RAdAK}^{a}, \mathrm{~A} \cdot \mathrm{Krmpot}^{b}$, \\ B. JELENKOVIC ${ }^{b}$ AND M. TRTICA ${ }^{a}$ \\ ${ }^{a}$ Institute of Nuclear Sciences "Vinca", Belgrade, Serbia \\ ${ }^{b}$ Institute of Physics, Belgrade, Serbia
}

\begin{abstract}
Interaction of pulsed femtosecond Ti:sapphire laser (160 fs), operating at high repetition rate $(75 \mathrm{MHz})$ at $800 \mathrm{~nm}$, with nickel-based superalloy Inconel 600 and tungsten-titanium (WTi) target was studied. The WTi target was in form of thin film deposited on silicon substrate. Low laser fluence of maximum $50 \mathrm{~mJ} / \mathrm{cm}^{2} \mathrm{had}$ modified the target surface during irradiation/exposure time of seconds or minutes. The radiation absorbed from the laser beam generates at the surface a series of effects, such as direct material vaporization, formation of clusters, etc. Morphological features of the targets can be summarized as: (a) intensive removal of material and crater appearance; (b) creation of nanostructures; (c) microcracking, etc. Ablation of Inconel 600 surface is effective, resulting in formation of holes with small diameter $(\leq 10 \mu \mathrm{m})$ and relatively large depth $(\leq 50 \mu \mathrm{m})$. In case of WTi target/thin film, the surrounding rim is not so expressed, and crater depths are lower. It can be concluded that the average laser power of the order of watts, pulse energies of the order of nanojoules and high repetition rates $(\mathrm{MHz}$ range) can successfully modify metallic materials.
\end{abstract}

PACS numbers: 42.62.-b, 61.80.Ba, 61.82.Bg, 79.20.Eb

\section{Introduction}

Studies of the surface modification of materials, including metals, by various types of energetic beams (laser beams among others), are of great fundamental and technological interest. Due to dramatic decrease of thermal effects, high precision processing of the materials using ultrashort laser pulses (both picosecond and femtosecond) is extremely advantageous [1,2]. Picosecond as well as femtosecond lasers are widely applied for the surface modification of metals [2, 3], alloys [4], biomaterials [5], etc.

Nickel-based superalloys are within the class of special alloys, characterized by extraordinary properties: high temperature and mechanical strength, admirable corrosion resistance, excellent thermal conductivity, resistance to aggressive atmosphere. They are therefore attractive for various applications in electronic, chemical and food industry, aerospace engineering, nuclear complexes, etc. [6]. Tungsten-titanium alloy which is studied in this work, too, as a refractory material, possesses extraordinary characteristics. It is attractive for microelectronic, gas sensor technology, protective coatings technology, etc. [7].

The interaction of WTi thin film and nickel-based superalloy Inconel 600 with femtosecond laser pulses, at a

* corresponding author; e-mail: jelsta@vinca.rs megahertz repetition rate, was not studied as we know. Our emphasis here is on studying the effects of a high repetition rate $(75 \mathrm{MHz})$ femtosecond laser, emitting radiation at $800 \mathrm{~nm}$, on the material's surface. Irradiation was performed at low energy - nanojoule regime. Special attention was paid to morphological surface modifications.

\section{Experimental}

Irradiations of the samples were performed with MIRA 900 Ti:sapphire femtosecond laser (Coherent Inc.) which was pumped by VERDI V-10 Nd-YVO bled laser (Coherent Inc.). MIRA 900 has 160 fs optical pulse length; repetition rate $75 \mathrm{MHz}$; wavelength $800 \mathrm{~nm}$ and linearly polarized beam. Maximum output power is up to $2 \mathrm{~W}$.

After MIRA 900, small part of the beam (about 1\%) is extracted for real time monitoring of femtosecond regime. Further, the beam passed through a beam expander (1:4), and finally it was focused by lens. Sample was placed at the precise $x-y-z$ holder perpendicular to the beam. Accuracy of the $z$-scan was about $10 \mu \mathrm{m}$. Pulse energy up to $20 \mathrm{~nJ}$ per pulse was delivered to the sample surface. Beam waist, at the focal point, was about $30 \mu \mathrm{m}$. All irradiations were carried out in air atmosphere.

The tungsten-titanium thin films were deposited on silicon substrate ( $n$-type) by dc sputtering of the $90 \% \mathrm{~W}-10 \% \mathrm{Ti}$ wt target. The deposition rate was $0.14 \mathrm{~nm} / \mathrm{s}$, while the thickness of thin film was $190 \mathrm{~nm}$. 
Prior to laser irradiation, the surface of the nickel-based superalloy Inconel 600 was prepared by a standard metallographic procedure. Estimated surface roughness of the sample (measured by AFM) was around $120 \mathrm{~nm}$

Surface morphology of the targets was monitored by optical (OM) and scanning electron microscopy (SEM). Specifying of the geometry of the ablated/damaged area was performed by profilometry.

\section{Results and discussion}

Morphological changes of WTi target after 1 and 7 min (pulse energy of $16 \mathrm{~nJ}$ ), and Inconel 600 target after $10 \mathrm{~s}$ (pulse energy of $17.3 \mathrm{~nJ}$ ) and $7 \mathrm{~min}$ (pulse energy of $20 \mathrm{~nJ}$ ) are presented in Figs. 1 and 2, respectively. Surface features can be summarized as: (a) intensive removal of material with crater appearance; (b) formation of redeposited material at near and further periphery; (c) sporadic microcracking of the inner and outer damage area, and (e) creation of spark-like plasma in front of the target.

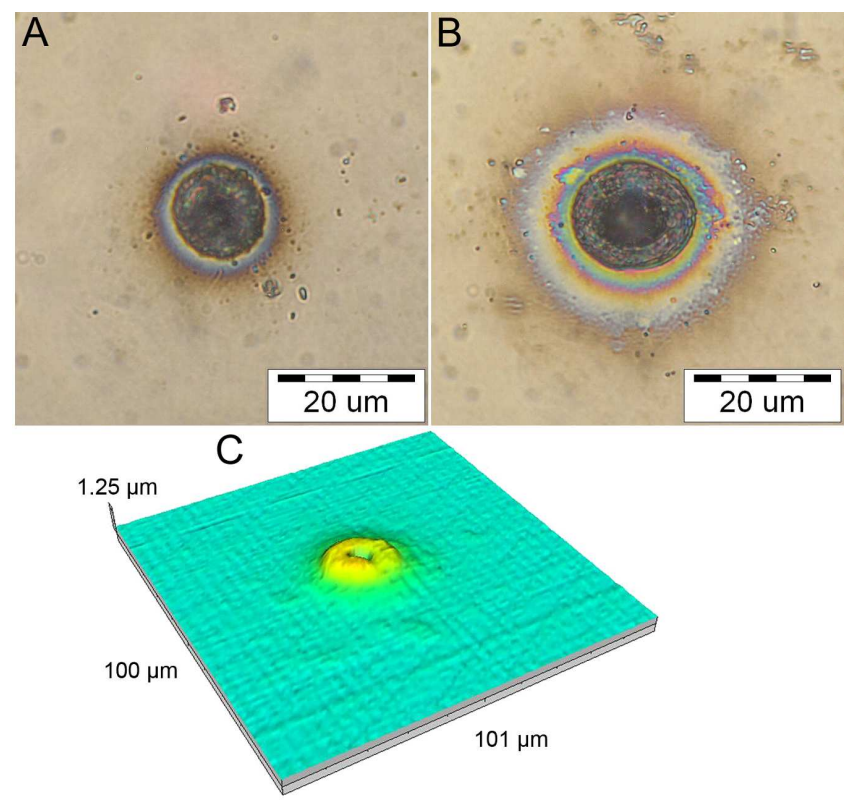

Fig. 1. Irradiation of WTi target with fs laser $\left(E_{\mathrm{p}}=\right.$ $16 \mathrm{~nJ})$. OM analysis after $1 \mathrm{~min}(\mathrm{~A})$ and $7 \mathrm{~min}(\mathrm{~B})$. Profilometer analysis of the damage formed after $7 \mathrm{~min}(\mathrm{C})$.

Interaction of femtosecond Ti:sapphire laser with both targets, under these conditions, resulted in the production of narrow damage area with the presence of a debris at the periphery. The equivalent crater diameter of the damage zone was maximum $\approx 10 \mu \mathrm{m}$. Damage diameter as a function of irradiation time, at the similar laser energy, typically increases with the increase of exposure time.

Generally, for irradiation at low repetition rates and low pulse energy only small portion of Gaussian beam close to the intensity peak has enough energy to ablate
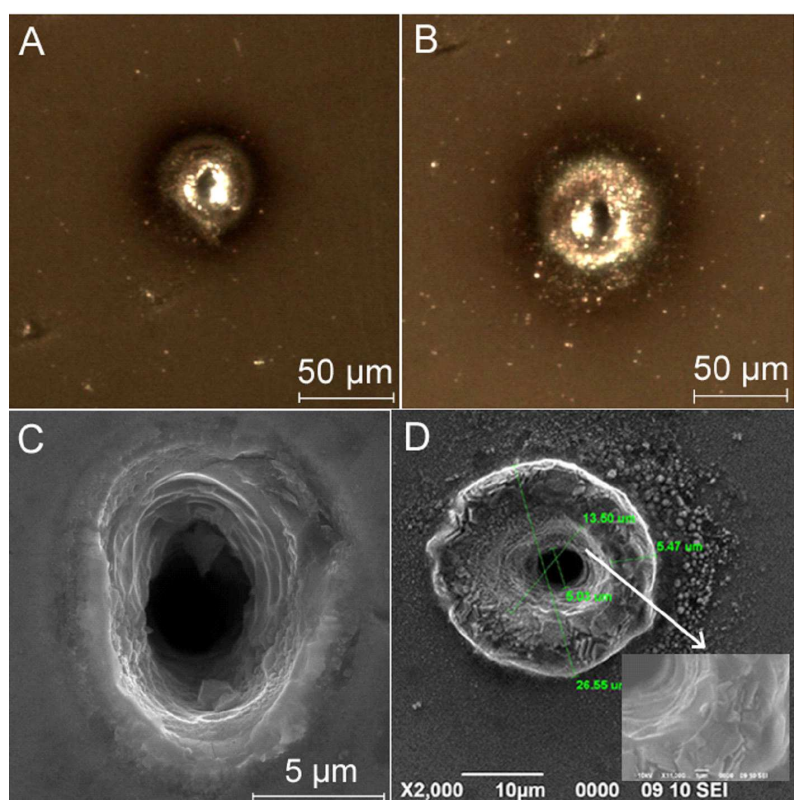

Fig. 2. Irradiation of Inconel 600 target with fs laser. $\mathrm{OM}$ and SEM analysis after $10 \mathrm{~s}, E_{\mathrm{p}}=17.3 \mathrm{~nJ}$

(A and $\mathrm{C}$ ), and after $7 \mathrm{~min}, E_{\mathrm{p}}=20 \mathrm{~nJ}(\mathrm{~B}$ and $\mathrm{D})$.

the material, thus resulting in crater diameter smaller than the laser beam waist. However, at higher repetition rate (order of $\mathrm{MHz}$ ) at the outer edges of the beam, thermal effect accounts for part of the ablation process even at fs pulse duration [8]. On the example of Inconel 600, it can be seen that for very short exposure times (order of seconds), the debris cohesion with the target is low. On the other hand, material ablation with longer exposure time, as a rule, resulted in a stronger debris cohesion [9]. Profilometry comparing of two targets after $7 \mathrm{~min}$ exposure showed that in the case of $\mathrm{WTi}$, the surrounding rim equals $\approx 1.25 \mu \mathrm{m}$, and for Inconel 600 it was $\approx 8 \mu \mathrm{m}$.

Longer irradiation time of 7 min resulted in a prominent debris presence at the periphery region and deeper craters in both materials. Preliminary focused ion beam (FIB) analysis shows lower crater depths in WTi samples $(\approx 10 \mu \mathrm{m})$ than in Inconel $600(\approx 50 \mu \mathrm{m})$ for $7 \mathrm{~min}$ irradiation time.

The time gap/length between two successive laser pulses in our experiments was $13.3 \mathrm{~ns}$ (repetition rate $75 \mathrm{MHz}$ ), so the lattice/target was completely, "cooled" during this time $[2,10]$. Ablation/modification with femtosecond laser pulses involves achieving of relativelly high intensity (in our experiments $\approx 10^{11} \mathrm{~W} / \mathrm{cm}^{2}$ ), precise material modification, etc.

More detailed SEM analysis of the Inconel 600 surface after exposure time of $7 \mathrm{~min}$ is given in Fig. 3 .

Preliminary observation/analysis of the rim structure (Fig. 3B) showed its difference in the crystallinity comparing to non-irradiated region. The presence of nanostructures at a further periphery was recorded on Inconel samples, particularly for longer laser irradiation 


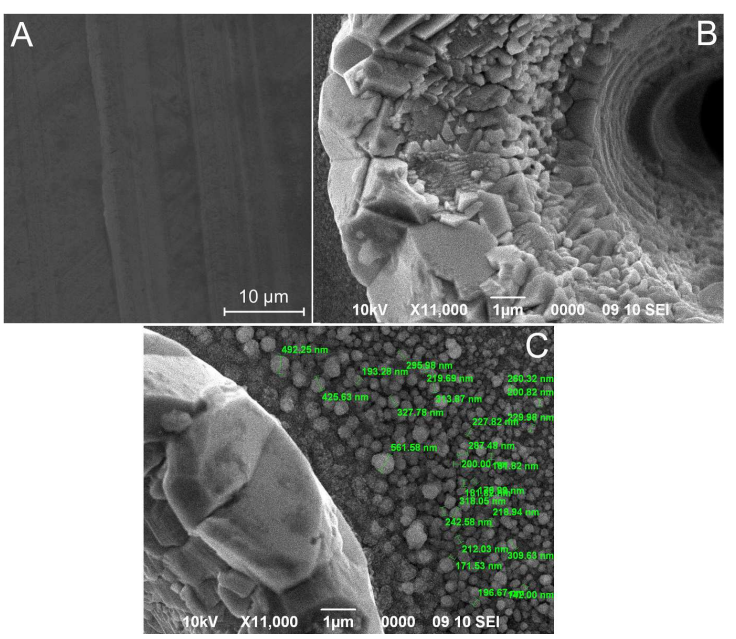

Fig. 3. SEM micrographs of Inconel 600 surface prior to irradiation (A), and after $7 \mathrm{~min}(\mathrm{~B}$ and $\mathrm{C}) . E_{\mathrm{p}}$ was $17.3 \mathrm{~nJ}(\mathrm{~B})$ and $14.6 \mathrm{~nJ}(\mathrm{C})$.

times (order of minutes). Dimensions of the individual nanograin were in the interval from $\approx 50$ to $\approx 200 \mathrm{~nm}$ (Fig. 3C). At low laser pulse energy/fluence regime the temperature at the surface is slightly above the evaporation temperature, thus the intensive material removal is possible via existence of a strong pressure in the absorbing region [11]. The ablated material, in this case, can include energetic clusters which can be redeposited close to the crater. The fast transition from solid to vapor as well as fast cooling probably affect the material resolidification, including the appearance of a new crystallization form at the rim of the crater.

\section{Conclusion}

A study of morphological changes of WTi and nickel-based superalloy Inconel 600 target induced by a femtosecond Ti:sapphire laser, operating at $75 \mathrm{MHz}$ at the wavelength of $800 \mathrm{~nm}$ is presented. Laser energy/fluence of maximum $20 \mathrm{~nJ} / 50 \mathrm{~mJ} / \mathrm{cm}^{2}$ was sufficient for surface modifications.
Generally, based on this study, it can be concluded that the average laser power of the order of watts, at high repetition rates and low pulse energies of the order of nanojoules, can successfully modify the metallic materials. The results for crater depths indicate a possibility of using this fs laser in the processes of precise drilling, with $\mu \mathrm{m}$ size holes in thin foils of the similar materials.

\section{Acknowledgments}

This research was supported by the Ministry of Science and Technological Development of the Republic of Serbia, contract Nos. 142065 and 141003.

\section{References}

[1] A. Semerok, B. Sallé, J.F. Wagner, G. Petite, Laser Part. Beams 20, 67 (2002).

[2] E.G. Gamaly, N.R. Madsen, M. Duering, A.V. Rode, V.Z. Kolev, B. Luther-Davies, Phys. Rev. B 71, 174405 (2005).

[3] A. Di Bernardo, C. Courtous, B. Cros, G. Matthiewussent, D. Batani, T. Desai, F. Strati, G. Lucchini, Laser Part. Beams 21, 59 (2003).

[4] M.S. Trtica, B.B. Radak, B.M. Gakovic, D.S. Milovanovic, D. Batani, T. Desai, Laser Part. Beams 27, 85 (2009).

[5] B.M. Mirdan, H.A. Jawad, D. Batani, V. Conte, T. Desai, R. Jafer, Laser Part. Beams 27, 103 (2009).

[6] C.B. In, Y.I. Kim, W.W. Kim, J.S. Kim, S.S. Chun, W.J. Lee, J. Nucl. Mater. 224, 71 (1995).

[7] S. Petrovic, B. Gakovic, D. Perusko, M. Trtica, B. Radak, P. Panjan, S. Miljanic, Appl. Surf. Sci. 254, 4013 (2008).

[8] S.M. Eaton, H. Zhang, P.R. Herman, F. Yoshino, L. Shah, J. Bovatsek, A.Y. Arai, Opt. Exp. 13, 4708 (2005).

[9] B. Tan, S. Panchatsharam, K. Venkatakrishnan, J. Phys. D, Appl. Phys. 42, 065102 (2009).

[10] X. Wang, X. Xu, J. Therm. Str. 25, 457 (2002).

[11] C. Cheng, X. Xu, Phys. Rev. B 72, 165415 (2005). 